\title{
Research on the influence of bubble curtains on shock wave fields of the underwater explosion
}

\author{
Thang Trong Dam ${ }^{1,}$, Viet Duc Tran ${ }^{2}$ \\ ${ }^{1}$ Military Technical Academy, Hanoi, Vietnam \\ ${ }^{2}$ Academy of Military Science and Technology, Hanoi, Vietnam
}

\begin{abstract}
ARTICLE INFO
ABSTRACT

Article history:

Received $18^{\text {th }}$ May 2021

Revised $16^{\text {th }}$ Aug. 2021

Accepted $13^{\text {th }}$ Sept. 2021

Keywords:

Bubble curtain,

Shock wave,

Underwater explosion.

Shock waves, which derive from explosions, generate reflected and refracted waves when propagating in the layered medium with various acoustic stiffness. Depending on the acoustic characteristic of each layer of the medium, properties of reflected and refracted waves will increase or decrease pressures/stresses at the investigated point of medium, compared to influences of explosive shock waves (incident waves) propagated in a homogeneous and isotropic medium. Based on this mechanical physical property, scientists have studied a diversity of solutions decreasing effects of explosive shock waves in various medium such as rock and soil, water, air. However, currently there have not been any comprehensive theoretical studies on the reduction in intensity of the underwater explosion shock wave when interacting with bubble curtain. By using the analytical method and the virtual explosive method, the paper presents the propagation rule of new waves formed when the underwater explosion shock wave interacts with the bubble curtain. The results showed that the more the thickness of the bubble curtain or the higher the bubble content or the longer the distance from the explosive to the curtain, the weaker the intensity of the shock wave when passing through the curtain.
\end{abstract}

Copyright (C) 2021 Hanoi University of Mining and Geology. All rights reserved.

${ }^{*}$ Corresponding author

E - mail: thangdt@lqdtu.edu.vn

DOI: 10.46326/JMES.2021.62(5).09 


\title{
Nghiên cứu ảnh hưởng của màn chắn bóng khí đến trường sóng nổ lan truyền trong môi trường nước
}

\author{
Đàm Trọng Thắng 1, *, Trần Đức Việt ${ }^{2}$ \\ ${ }^{1}$ Học viện Kỹ thuật Quân sự, Hà Nội, Việt Nam \\ 2 Viện Khoa họ Công nghệ Quân sự, Hà Nội, Việt Nam
}

THÔNG TIN BÀI BÁO T TÓM TẮT

Quá trình:

Nhận bài 18/5/2021

Sửa xong 16/8/2021

Chap nhận đăng 13/9/2021

Từ khóa:

Màn chắn bọt khí,

Nổ dưới nước,

Sóng xung kích.
Sóng xung kích do nổ khi lan truyền trong môi trường phân lớp có độ cúng âm học khác nhau sẽ làm phát sinh các sóng phản xạ và sóng khúc xạ. Tùy theo đặc tính âm học của các lóp môi trường mà đặc tính của sóng phản xa và khúc xạ sẽ làm tăng hay giảm áp suất hoặc ứng suất của môi truờng tại điểm khảo sát so với tác dụng của sóng xung kích do nổ (sóng tới) khi lan truyền trong môi trường đồng nhất, đẳng hướng. Dựa trên đặc tính co lý này, các nhà khoa học đã nghiên cúu nhiều giải pháp giảm thiểu tác dụng của sóng nổ trong các môi trường đất đá, nước, không khí. Tuy nhiên, hiện nay chưa có một công trình lý thuyết nghiên cưu toàn diện về sự suy giảm của sóng xung kích do nổ trong nước tạo ra khi gặp màn chắn bóng khí. Bằng phương pháp giải tích và phương pháp lượng nổ ảo, bài báo đã xác định được quy luật lan truyền của các sóng mới hình thành khi sóng nổ lan truyền trong nước gặp màn chắn bóng khí. Kết quả nghiên cứu cũng chỉ ra càng tăng chiều dày lớp màn chắn bóng khí hoặc càng tăng hàm lượng bóng khí hay càng tăng khoảng cách tù̀ lượng nổ đến màn bóng khí thì cường độ sóng nổ khi đi qua màn chắn suy giảm càng mạnh.

C 2021 Trường Đại học Mỏ - Địa chất. Tất cả các quyền được bảo đảm.

\section{Mở đầu}

Các nghiên cứu về vụ nổ dưới nước và sự lan truyền của sóng nổ trong nước chủ yếu được thực hiện trong và sau chiến tranh thế giới thứ hai (Cole R. H, 1948; Oplenko L. P, 2004). Tác dụng cơ học

\footnotetext{
*Tác giả liên hệ

E - mail: thangdt@lqdtu.edu.vn

DOI: 10.46326/JMES.2021.62(5).09
}

nổ của các vụ nổ dưới nước ở gần mặt thoáng bị suy giảm và đã được chỉ ra là do ảnh hưởng của mặt thoáng.

Đàm Trọng Thắng và nnk. (2020) đã chỉ ra sóng nổ từ môi trường nước khi lan truyền qua mặt phân cách nước - nước chứa bóng khí bị phân rã thành sóng phản xạ giãn chuyển động ngược về môi trường nước ban đầu và sóng khúc xạ nén lan truyền sang môi trường nước chứa bóng khí, trong đó cường độ của sóng khúc xạ luôn nhỏ hơn cường độ của sóng tới ban đầu và sự suy giảm này 
càng lớn khi độ cứng truyền âm của môi trường nước chứa bóng khí càng nhỏ.

Mặt khác, Đàm Trọng Thắng và Trần Đức Việt (2020) cũng chỉ ra trong môi trường nước chứa bóng khí thì áp suất của môi trường càng nhỏ khi độ cứng truyền âm của môi trường càng nhỏ.

Từ các kết quả trên có thể thấy, sóng nổ có khả năng bị triệt tiêu hoàn toàn khi từ môi trường nước lan truyền sang môi trường nước chứa bóng khí. Hiện tượng này rất có ích trong thực tế nếu môi trường nước chứa bóng khí là hữu hạn ở dạng màn chắn để có thể bố trí chắn ngang phương truyền sóng nổ theo hướng cần bảo vệ công trình, thiết bị,... ngập nước khi thi công nổ dưới nước.

Bài báo này xác định quy luật lan truyền của các sóng hình thành khi sóng nổ trong nước tương tác với màn chắn bóng khí cũng như xác định hiệu quả làm suy giảm cường độ sóng nổ của màn chắn bóng khí theo một số thông số đặc trưng của màn chắn và môi trường.

\section{Sự phân rã sóng nổ tại mặt phân cách giữa hai môi trường}

Xét hai môi trường lý tưởng không có độ bền và nội ma sát, bán vô tận $A$ và $B$ phân cách nhau bởi mặt phân cách $\Delta$. Trong môi trường $A$ đặt một lượng nổ $\mathrm{C}_{0}$ ở vị trí cách mặt phân cách $\Delta$ một khoảng a theo phương pháp tuyến với mặt phân cách.

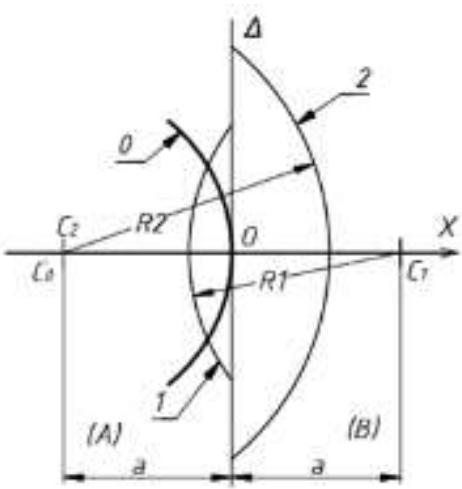

(0- sóng tới; 1- sóng phản xạ; 2- sóng khúc xạ)

\section{Hình 1. Mô hình phân rã sóng tới tại mặt phân cách giữa hai môi trường}

Khi $\mathrm{C}_{0}$ nổ, tạo ra sóng xung kích 0 lan truyền trong môi trường $\mathrm{A}$; khi sóng tới 0 lan truyền tới mặt phân cách $\Delta$ xuất hiện sóng phản xạ 1 hướng ngược từ mặt phân cách về môi trường $A$ và sóng khúc xạ 2 lan truyền trong môi trường $B$ (Hình 1).
Đặt trục $\mathrm{OX}$ trùng với pháp tuyến của mặt phân cách đi qua $\mathrm{C}_{0}$ và hướng từ môi trường $\mathrm{A}$ sang môi trường $\mathrm{B}$, điểm $\mathrm{O}$ nằm trên mặt phân cách.

Cường độ và tốc độ dịch chuyển tương ứng của các hạt trong sóng phản xạ và sóng khúc xạ xác định từ điều kiện liên tục đối với ứng suất và tốc độ trên mặt phân cách. Đối với trường hợp sóng phản xạ thẳng đang xét, được xác định theo phương trình sau (Đàm Trọng Thắng và nnk, 2015):

$$
\begin{aligned}
& \sigma_{T}+\sigma_{P X}=\sigma_{K X} \\
& u_{T}+u_{P X}=u_{K X}
\end{aligned}
$$

Trong đó:

$\sigma_{T}, \sigma_{P X}, \sigma_{K X}$ - ứng suất $(\mathrm{Pa})$ tương ứng trong sóng tới, sóng phản xạ, sóng khúc xạ;

$u_{T}, u_{P X}, u_{K X}$ - tốc độ dịch chuyển $(\mathrm{m} / \mathrm{s})$ của các hạt trong sóng tới, sóng phản xạ, sóng khúc xạ.

Ứng suất trong sóng lan truyền ở mỗi thời điểm và mỗi điểm trong môi trường được rút ra từ định luật bảo toàn xung lượng (Đàm Trọng Thắng và nnk., 2015):

$$
u= \pm \frac{\sigma}{\rho . c}
$$

Trong đó: dấu (+) và (-) ứng với ứng suất nén và kéo; $\rho, c$ - mật độ và tốc độ truyền âm trong môi trường.

Từ (1), (3) và sau một số phép biến đổi, rút ra:

$$
\begin{aligned}
\sigma_{K X} & =\frac{2 \rho_{B} \cdot c_{B}}{\rho_{A} \cdot c_{A}+\rho_{B} \cdot c_{B}} \sigma_{T} \\
\sigma_{P X} & =-\frac{\rho_{A} \cdot c_{A}-\rho_{B} \cdot c_{B}}{\rho_{A} \cdot c_{A}+\rho_{B} \cdot c_{B}} \sigma_{T}
\end{aligned}
$$

Ký hiệu các đại lượng:

$$
\begin{gathered}
K_{K X}=\frac{2 \rho_{B} \cdot c_{B}}{\rho_{A} \cdot c_{A}+\rho_{B} \cdot c_{B}}=\frac{2 Z_{B}}{Z_{A}+Z_{B}} \\
K_{P X}=-\frac{\rho_{A} \cdot c_{A}-\rho_{B} \cdot c_{B}}{\rho_{A} \cdot c_{A}+\rho_{B} \cdot c_{B}}=-\frac{Z_{A}-Z_{B}}{Z_{A}+Z_{B}} \\
Z_{A}=\rho_{A} \cdot c_{A} ; Z_{B}=\rho_{B} \cdot c_{B}
\end{gathered}
$$

$K_{K X}, K_{P X}$ - hệ số khúc xạ và hệ số phản xạ. Các hệ số này đặc trưng cho giá trị ứng suất trong sóng khúc xạ, sóng phản xạ hình thành tại mặt phân cách của 2 môi trường khi có sóng tới lan truyền đến; $Z_{A}, Z_{B}$ - độ cứng truyền âm $\left(\mathrm{kg} \cdot \mathrm{m}^{-2} \cdot \mathrm{s}^{-2}\right)$ của môi trường $A$ và $B$. 
Do các môi trường $A, B$ đang xét là các môi trường lý tưởng không có độ bền và nội ma sát, nên theo Oplenko L. P, 2004:

$$
p=-\sigma
$$

Từ (4), (8) và (9), biên độ sóng khúc xạ, phản xạ tại mặt phân cách theo biên độ sóng tới như sau:

$$
\begin{aligned}
& p_{K X}^{*}=K_{K X} \cdot p^{*} \\
& p_{P X}^{*}=K_{P X} \cdot p^{*}
\end{aligned}
$$

Trong đó: $p^{*}, p_{P X}^{*}, p_{K X}^{*}$ - biên độ áp suất (Pa) của sóng tới, sóng phản xạ, sóng khúc xạ tại điểm 0 trên mặt phân cách.

\section{Sự tương tác của sóng nổ với màn chắn bóng khí trong môi trường nước vô tận}

Xét môi trường nước vô tận có một màn bóng khí vô tận có chiều dày $b(\mathrm{~m})$. Gọi khu vực môi trường nước bên trái màn bóng khí là môi trường I, màn bóng khí là môi trường II và bên phải màn bóng khí là môi trường III. Môi trường I và II phân cách nhau bởi mặt $\Delta_{1}$, môi trường II và III phân cách nhau bởi $\Delta_{2}$ (Hình 2).

Trong môi trường I đặt một lượng nổ $\mathrm{C}_{0}$ ở vị trí cách $\Delta_{1}$ một khoảng $a$ theo phương pháp tuyến với nó. Khi $\mathrm{C}_{0}$ nổ, tạo ra sóng xung kích 0 lan truyền trong môi trường $\mathrm{I}$; khi sóng 0 lan truyền tới $\Delta_{1}$ phân rã thành sóng phản xạ 10 hướng ngược từ $\Delta_{1}$ về môi trường I và sóng khúc xạ 20 lan truyền trong môi trường II. Sóng khúc xạ 20 lan truyền tới $\Delta_{2}$ phân rã thành sóng phản xạ 30 lan truyền ngược từ $\Delta_{2}$ về $\Delta_{1}$ và sóng khúc xạ 40 lan truyền sang môi trường III.

Khi sóng phản xạ 30 lan truyền tới $\Delta_{1}$ phân rã thành sóng phản xạ 21 chuyển động từ $\Delta_{1}$ về $\Delta_{2}$ và sóng khúc xạ 11 từ $\Delta_{1}$ sang môi trường I. Sóng phản xạ 21 tới $\Delta_{2}$ sẽ phân rã thành sóng phản xạ 31 hướng từ $\Delta_{2}$ sang $\Delta_{1}$ và sóng khúc xạ 41 hướng từ $\Delta_{2}$ tới môi trường III. Quá trình phân rã sóng tại các mặt phân cách cứ lặp đi lặp lại như vậy đến khi biên độ sóng phản xạ trong II suy giảm về áp suất môi trường.

Phân tích trên thấy rằng: từ sóng xung kích 0 ban đầu, sau khi tương tác với màn chắn bóng khí trong môi trường nước vô tận thì tại các mặt phân cách $\Delta_{1}, \Delta_{2}$ sẽ hình thành một loạt các sóng lan truyền sang môi trường III (các sóng khúc xạ 40, $41,42, \ldots$ ) và sang môi trường I (sóng phản xạ 10 và các sóng khúc xạ 11,12,...).

Gọi $r_{0}$ là bán kính $(\mathrm{m})$ của lượng nổ $\mathrm{C}_{0}$. Trong phạm vi của nghiên cứu này, các tác giả chỉ xét với lượng nổ cách mặt phân cách một lượng $a$ thỏa mãn $a>10 r_{0}$ và áp suất trên mặt sóng <100MPa. Với điều kiện này, tốc độ lan truyền sóng nổ trong nước được coi bằng tốc độ truyền âm trong nước (Oplenko L. P, 2004).

Đặt trục $\mathrm{O}_{1} \mathrm{X}$ trùng với pháp tuyến của mặt phân cách đi qua $\mathrm{C}_{0}$ và hướng từ môi trường I sang môi trường III, điểm $\mathrm{O}_{1}$ nằm trên $\Delta_{1}$, điểm $\mathrm{O}_{2}$ là giao của $\mathrm{O}_{1} \mathrm{X}$ với $\Delta_{2}$.

Để đánh giá cường độ của các sóng mới hình thành trên mặt phân cách, cần xác định quy luật

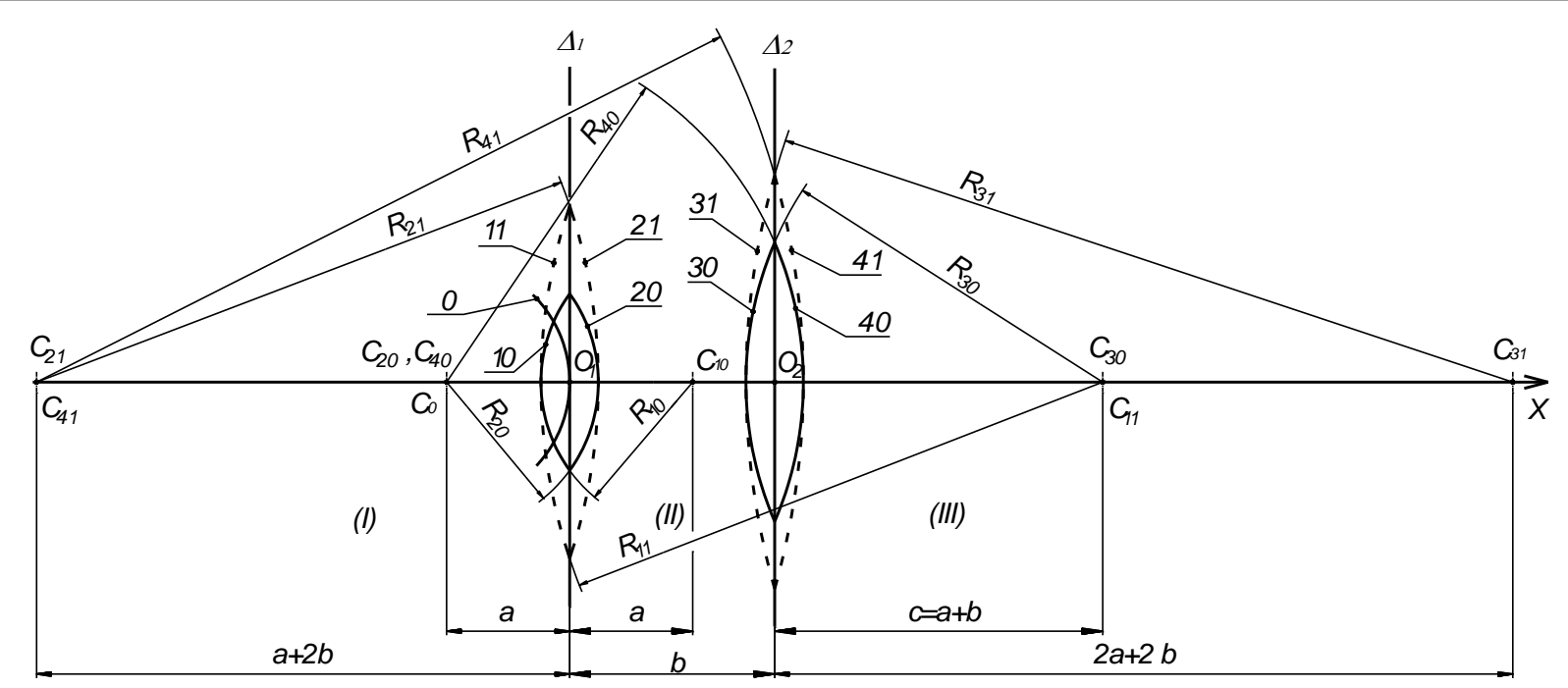

Hình 2. Mô hình tương tác của sóng nổ với màn chắn bóng khí trong môi trường nước vô tận. 
thay đổi áp suất trên mặt sóng của các sóng đó trên trục $\mathrm{O}_{1} \mathrm{X}$.

\subsection{Xác định quy luật lan truyền các sóng hình thành tại các mặt phân cách trong lần phân rã sóng đầu tiên}

Theo Hồ Sĩ Giao và nnk. (2010), áp suất trên mặt sóng nổ hình cầu trong môi trường chất lỏng vô tận là một hàm của khoảng cách, có thể được biểu diễn ở dạng không thứ nguyên như sau:

$$
\frac{p-p_{m n}}{p_{m n}}=A \cdot\left(\frac{r_{0}}{R}\right)^{\gamma}
$$

Trong đó:

p - áp suất trên mặt sóng nổ (Pa) tại vị trí cách tâm lượng nổ hình cầu có bán kính $r_{0}(\mathrm{~m})$ một khoảng $R(\mathrm{~m})$;

$p_{m n}$ - áp suất tại mặt thoáng chất lỏng $(\mathrm{Pa})$;

$A, \gamma$ - các hệ số thực nghiệm phụ thuộc bản chất môi trường; với nước: $A=14700$ và $\gamma=1,13$.

Sử dụng lý thuyết lượng nổ ảo để xác định các sóng phản xạ, khúc xạ xuất hiện tại mặt phân cách khi sóng tới phân rã, sẽ có tương ứng với các sóng $10,20,30,40$ là các lượng nổ ảo $\mathrm{C}_{10}, \mathrm{C}_{20}, \mathrm{C}_{30}, \mathrm{C}_{40}$ đặt ở các vị trí xác định theo các mặt phân cách (Hình 2 ), cụ thể: $\mathrm{C}_{10}$ đối xứng với $\mathrm{C}_{0}$ ban đầu qua $\Delta_{1} ; \mathrm{C}_{30}$ đối xứng với $\mathrm{C}_{0}$ ban đầu qua $\Delta_{2} ; \mathrm{C}_{20}, \mathrm{C}_{40}$ ở vị trí trùng vị trí của $\mathrm{C}_{0}$.

Áp dụng (12), sẽ xác định được quy luật thay đổi áp suất trên mặt sóng tại các vị trí cách tâm lượng nổ (thật hoặc ảo) một khoảng R như sau (các sóng minh họa ở Hình 2):

+ Với sóng xung kích 0 ban đầu lan truyền trong môi trường $\mathrm{I}(\mathrm{R} \leq \mathrm{a})$ :

$$
\frac{p_{0}-p_{m n}}{p_{m n}}=14700 \cdot\left(\frac{r_{C 0}}{R}\right)^{1,13}
$$

+ Với sóng phản xạ 10 lan truyền trong môi trường $\mathrm{I}(\mathrm{R} \geq \mathrm{a})$ :

$$
\frac{p_{10}-p_{m n}}{p_{m n}}=14700 \cdot\left(\frac{r_{C 10}}{R}\right)^{1,13}
$$

+ Với sóng khúc xạ 20 lan truyền trong môi trường II $(\mathrm{a} \leq \mathrm{R} \leq \mathrm{a}+\mathrm{b})$ :

$$
\frac{p_{20}-p_{m n}}{p_{m n}}=A .\left(\frac{r_{C 20}}{R}\right)^{\gamma}
$$

+ Với sóng phản xạ 30 lan truyền trong môi trường II $(\mathrm{a}+\mathrm{b} \leq \mathrm{R} \leq \mathrm{a}+2 \mathrm{~b})$ :

$$
\frac{p_{30}-p_{m n}}{p_{m n}}=A \cdot\left(\frac{r_{C 30}}{R}\right)^{\gamma}
$$

+ Với sóng khúc xạ 40 lan truyền trong môi trường III $(\mathrm{R} \geq \mathrm{a}+\mathrm{b})$ :

$$
\frac{p_{40}-p_{m n}}{p_{m n}}=14700 \cdot\left(\frac{r_{C 40}}{R}\right)^{1,13}
$$

Trong đó:

$a, b$ - lần lượt là khoảng cách từ lượng nổ ban đầu $\mathrm{C}_{0}$ tới $\Delta_{1}$ và độ rộng môi trường II $(\mathrm{m})$;

$r_{C O}$ - bán kính lượng nổ ban đầu $\mathrm{C}_{0}(\mathrm{~m})$;

$r_{C 10}, r_{C 20}, r_{C 30}, r_{C 40}$ - lần lượt là bán kính $(\mathrm{m})$ của các lượng nổ ảo $\mathrm{C}_{10}, \mathrm{C}_{20}, \mathrm{C}_{30}, \mathrm{C}_{40}$ của các sóng 10 , 20,30, 40 hình thành ở lần phân rã đầu tiên. Bán kính các lượng nổ ảo này xác định từ quan hệ của các sóng phản xạ, khúc xạ theo sóng tới tại mặt phân cách giữa 2 môi trường.

Áp dụng các công thức (6), (8) và (10), (11) tại điểm $0_{1}$ trên mặt phân cách $\Delta_{1}$ giữa môi trường I và II:

$$
\begin{aligned}
& p_{10}^{*}=K_{P X 12} \cdot p_{0}^{*} \\
& p_{20}^{*}=K_{K X 12} \cdot p_{0}^{*} \\
& K_{K X 12}=\frac{2 Z_{2}}{Z_{1}+Z_{2}} \\
& K_{P X 12}=-\frac{Z_{1}-Z_{2}}{Z_{1}+Z_{2}}
\end{aligned}
$$

Áp dụng các công thức (6), (8) và (10), (11) tại điểm $\mathrm{O}_{2}$ trên mặt phân cách $\Delta_{2}$ giữa môi trường II và III:

$$
\begin{aligned}
& p_{30}^{* *}=K_{P X 23} \cdot p_{20}^{* *} \\
& p_{40}^{* *}=K_{K X 23} \cdot p_{20}^{* *} \\
& K_{K X 23}=\frac{2 Z_{3}}{Z_{2}+Z_{3}} \\
& K_{P X 23}=-\frac{Z_{2}-Z_{3}}{Z_{2}+Z_{3}}
\end{aligned}
$$

Trong đó :

$p_{0}^{*}, p_{10}^{*}, p_{20}^{*}$ - áp suất (Pa) trên mặt sóng tới 0 , sóng phản xạ 10 và sóng khúc xạ 20 tại mặt phân cách $\Delta_{1}$;

$p_{20}^{* *}, p_{30}^{* *}, p_{40}^{* * *}$ - áp suất $(\mathrm{Pa})$ trên mặt sóng tới 20, sóng phản xạ 30 và sóng khúc xạ 40 tại mặt phân cách $\Delta_{2}$;

$Z_{1}, Z_{2}, Z_{3}$ - độ cứng truyền âm $\left(\mathrm{kg} \cdot \mathrm{m}^{-2} \cdot \mathrm{s}^{-2}\right)$ của môi trường I, II, III.

Áp dụng (13), (14) với sóng tới 0 và sóng phản xạ 10 tại điểm $0_{1}$, kết hợp với $(18)$ và sau một vài biến đổi thu được: 
14700. $\left(\frac{r_{C 10}}{R}\right)^{1,13}=\left(\frac{a}{R}\right)^{1,13} \cdot\left[K_{P X 12} \cdot 14700 \cdot\left(\frac{r_{C 0}}{a}\right)^{1,13}+K_{P X 12}-1\right]$

Thực hiện các phép biến đổi tương tự, sẽ có các quan hệ sau:

$A \cdot\left(\frac{r_{C 20}}{R}\right)^{\gamma}=\left(\frac{a}{R}\right)^{\gamma} \cdot\left[K_{K X 12} \cdot 14700 \cdot\left(\frac{r_{C 0}}{a}\right)^{1,13}+K_{K X 12}-1\right]$
$A \cdot\left(\frac{r_{C 30}}{R}\right)^{\gamma}=K_{P X 23} \cdot A \cdot\left(\frac{r_{C 20}}{R}\right)^{\gamma}+\left(K_{P X 23}-1\right) \cdot\left(\frac{a+b}{R}\right)^{\gamma}$
$14700 \cdot\left(\frac{r_{C 40}}{R}\right)^{1,13}=\left(\frac{a+b}{R}\right)^{1,13} \cdot$
$\left[K_{K X 23} \cdot\left(\frac{a}{a+b}\right)^{\gamma} \cdot\left(K_{K X 12} \cdot 14700 \cdot\left(\frac{r_{C 0}}{a}\right)^{1,13}+K_{K X 12}-1\right)+K_{K X 23}-1\right]$

Thay (26), (29) vào (13), (17) có các biểu thức xác định áp suất tại bán kính $R$ trên các mặt sóng của các sóng mới hình thành ở lần phân rã đầu tiên như sau:

+ Với sóng phản xạ 10 lan truyền trong môi trường I $(\mathrm{R} \geq \mathrm{a})$ :

$\frac{p_{10}-p_{m n}}{p_{m n}}=\left(\frac{a}{R}\right)^{1,13} \cdot\left[K_{P X 12} \cdot 14700 \cdot\left(\frac{r_{C 0}}{a}\right)^{1,13}+K_{P X 12}-1\right]$

+ Với sóng khúc xạ 20 lan truyền trong môi trường II $(\mathrm{a} \leq \mathrm{R} \leq \mathrm{a}+\mathrm{b})$ :

$\frac{p_{20}-p_{m n}}{p_{m n}}=\left(\frac{a}{R}\right)^{\gamma} \cdot\left[K_{K X 12} \cdot 14700 \cdot\left(\frac{r_{C 0}}{a}\right)^{1,13}+K_{K X 12}-1\right]$

+ Với sóng phản xạ 30 lan truyền trong môi trường II $(\mathrm{a}+\mathrm{b} \leq \mathrm{R} \leq \mathrm{a}+2 \mathrm{~b})$ :

$$
\begin{aligned}
& \frac{p_{30}-p_{m n}}{p_{m n}}=K_{P X 23} \cdot\left[\left(\frac{a}{R}\right)^{\gamma} \cdot\left(K_{K X 12} \cdot 14700 \cdot\left(\frac{r_{C 0}}{a}\right)^{1,13}+K_{K X 12}-1\right)\right]+ \\
& +\left(K_{P X 23}-1\right) \cdot\left(\frac{a+b}{R}\right)^{\gamma}
\end{aligned}
$$

+ Với sóng khúc xạ 40 lan truyền trong môi trường III $(\mathrm{R} \geq \mathrm{a}+\mathrm{b})$ :

$$
\begin{aligned}
& \frac{p_{40}-p_{m n}}{p_{m n}}=\left(\frac{a+b}{R}\right)^{1,13} \cdot \\
& {\left[K_{K X 23} \cdot\left(\frac{a}{a+b}\right)^{\gamma} \cdot\left(K_{K X 12} \cdot 14700 \cdot\left(\frac{r_{C 0}}{a}\right)^{1,13}+K_{K X 12}-1\right)+K_{K X 23}-1\right]}
\end{aligned}
$$

Từ (30), (33) thấy rằng: các sóng xuất hiện trong lần phân rã sóng đầu tiên là hoàn toàn xác định khi biết được các hệ số khúc xạ, phản xạ tại 2 mặt phân cách và các thông số quy luật lan truyền của sóng nổ trong môi trường nước chứa bọt khí (các hệ số thực nghiệm $A, \gamma$ ).

Các hệ số khúc xạ, phản xạ tại 2 mặt phân cách xác định như sau:

Gọi $\rho_{10}, \rho_{20}, \rho_{30}$ lần lượt là mật độ $\left(\mathrm{kg} / \mathrm{m}^{3}\right)$ của môi trường I, II, III ở trạng thái ban đầu có áp suất $p_{0} ; \rho_{1}, \rho_{2}, \rho_{3}$ lần lượt là mật độ $\left(\mathrm{kg} / \mathrm{m}^{3}\right)$ của môi trường I, II, III ở trạng thái có áp suất p. Gọi $c_{1}, c_{2}$, $c_{3}$ lần lượt là tốc độ truyền âm $(\mathrm{m} / \mathrm{s})$ trong các môi trường I, II, III. Gọi $c_{n}$, $c_{k 0}$ là tốc độ truyền âm (m/s) trong chất lỏng, chất khí ở điều kiện áp suất khí quyển.

Riêng với môi trường II: gọi $\alpha_{n 0}, \alpha_{k 0}$ là tỷ lệ thể tích tương ứng với thành phần lỏng, khí trong môi trường ở trạng thái ban đầu và $\rho_{n 0}, \rho_{k 0}$ là các mật độ $\left(\mathrm{kg} / \mathrm{m}^{3}\right)$ của các pha lỏng, khí tương ứng.

Ta có các quan hệ như sau:

$$
\begin{aligned}
& \alpha_{n 0}+\alpha_{k 0}=1 \\
& \rho_{20}=\alpha_{n 0} \rho_{n 0}+\alpha_{k 0} \rho_{k 0} \\
& \rho_{10}=\rho_{30}=\rho_{n 0}
\end{aligned}
$$

Theo Đàm Trọng Thắng và Trần Đức Việt (2020), độ cứng truyền âm của các môi trường I, II, III xác định theo các biểu thức sau:

$$
\begin{gathered}
Z_{1}=\sqrt{\frac{\rho_{n 0}}{\beta_{n}} \cdot\left(\frac{p-p_{m n}}{\rho_{n 0} \cdot c_{n 0}^{2}} \cdot K_{n}+1\right)^{\frac{1}{K_{n}}}} \\
Z_{2} \\
Z_{3}=\sqrt{\frac{\rho_{20}}{\left(\alpha_{k 0} \cdot\left(\frac{p}{p_{k 0}}\right)^{\frac{-1}{K_{k}}}+\alpha_{n 0} \cdot\left(\frac{p-p_{m n}}{\rho_{n 0} \cdot c_{n 0}^{2}} \cdot K_{n}+1\right)^{\frac{-1}{K_{n}}}\right) \cdot\left(\alpha_{k 0} \cdot \frac{1}{K_{k} \cdot p}+\alpha_{n 0} \cdot \beta_{n n}\right)}}
\end{gathered}
$$

Áp suất môi trường nước tại vị trí khảo sát xác định theo độ sâu $w$ tại đó như sau:

$$
p=p_{m n}+\rho_{n 0} . g . \mathrm{w}
$$


Trong đó:

$\beta_{n}$ - độ nén của nước, thay đổi khi nhiệt độ môi trường thay đổi; tuy nhiên, theo Domenico (1982) các ảnh hưởng này là nhỏ và có thể xác định: $\beta_{n}=4,382 \cdot 10^{-10}\left(\mathrm{~Pa}^{-1}\right)$;

$p, p_{m n}$ - áp suất ở trạng thái khảo sát và áp suất ban đầu của khí quyển trên mặt nước (Pa);

$K_{n}$ - chỉ số đa biến thực nghiệm của môi trường nước, theo Lyakhov $\mathrm{G}$. $\mathrm{M}, 1982$ thì $\mathrm{K}_{\mathrm{n}}=3$;

$K_{k}$ - chỉ số đa biến của chất khí trong bóng khí; $g=9,81 \mathrm{~m} / \mathrm{s}^{2}$ - gia tốc trọng trường.

Trong điều kiện tiêu chuẩn: $c_{n 0}=1.500 \mathrm{~m} / \mathrm{s}$; $c_{k 0}=340 \mathrm{~m} / \mathrm{s} ; K_{k}=1,4 ; \rho_{n 0}=1.000 \mathrm{~kg} / \mathrm{m}^{3}$; $\rho_{k 0}=1,27 \mathrm{~kg} / \mathrm{m}^{3}$.

Khảo sát $Z_{1}-Z_{2}$ với $\alpha_{k 0}=0 . .1$ và $p=p_{m n} \ldots 1.000$ $\mathrm{MPa}$ (Hình 3), thấy rằng: $Z_{1}-Z_{2} \geq 0$

Kết hợp với (37) và (39), ta có:

$$
Z_{1}=Z_{3} \geq Z_{2}
$$

với $\alpha_{k 0}=0 \ldots 1$ và $p=p_{m n} \ldots 1.000 \mathrm{MPa}$.

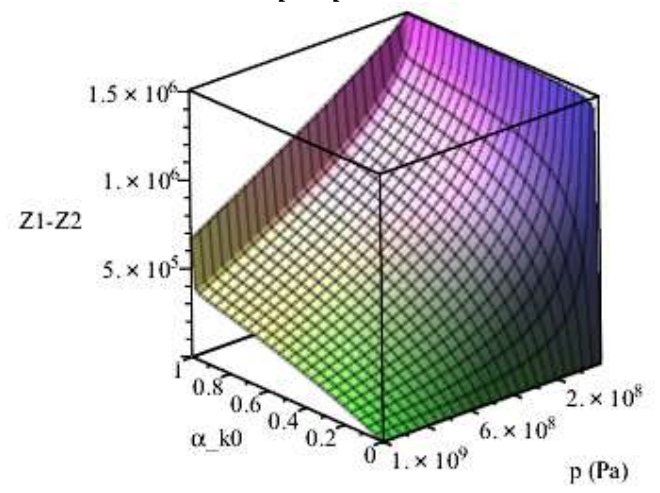

Hình 3. Khảo sát $Z_{1}-Z_{2}$ với $\alpha_{k 0}=0 . .1$ và $p=p_{m n . .} 1000 \mathrm{MPa}$

\subsection{Xác định quy luật thay đổi cưòng độ các sóng hình thành tại các mặt phân cách màn chắn bóng khí trong các lần phân rã sóng về sau}

Như trên đã trình bày, sau lần phân rã đầu tiên, sóng 30 hình thành và lan truyền trong môi trường II (Hình 2), khi gặp các mặt phân cách của màn chắn bọt khí với nước tiếp tục phân rã thành các sóng khác. Quá trình này sẽ dừng lại khi các sóng phản xạ 3i hoặc $2 \mathrm{i}$ suy giảm tới áp suất môi trường. Thực vậy, từ (41), (24) và (25) có:

$$
0 \leq K_{P X 23} \leq 1 \leq K_{K X 23} \leq 2
$$

Tương tự, cũng có:

$$
0 \leq K_{P X 21} \leq 1 \leq K_{K X 21} \leq 2
$$

Tù̀ (42) và (43) nhận thấy: các sóng phản xạ $3 \mathrm{i}$ và $2 \mathrm{i}$ sau khi hình thành luôn có biên độ nhỏ hơn các sóng tới tạo ra nó lần lượt là $2 \mathrm{i}$ và $3(\mathrm{i}-1)$. Mặt khác, các sóng này lại luôn suy giảm do tổn hao năng lượng trong quá trình lan truyền. Nên các sóng $3 i$ và $2 i$ càng hình thành sau càng yếu.

Do các sóng $3 i$ càng về sau càng yếu nên các sóng khúc xạ 4i luôn yếu hơn sóng 4(i-1) hình thành của lần phân rã sóng trước đó.

Với lý do như vậy, để đánh giá hiệu quả làm suy giảm áp suất trên mặt sóng nổ của màn chắn bọt khí, chỉ cần đánh giá hiệu quả làm suy giảm với sóng khúc xạ 40 được hình thành trong lần phân rã sóng đầu tiên.

\subsection{Xác định hệ số suy giảm áp suất trên mặt sóng nổ do ảnh hưởng của màn chắn bóng khí trong môi trường nước vô tận}

Như phần 3.2 đã phân tích, để xác định hệ số suy giảm áp suất trên mặt sóng nổ do ảnh hưởng của màn chắn bóng khí trong môi trường nước vô tận, chỉ cần đánh giá tỷ số độ lớn của áp suất trên mặt sóng khúc xạ tạo thành từ lần phân rã đầu tiên sau màn chắn bóng khí và giá trị tương ứng của áp suất sóng nổ tại vị trí đó khi không có màn chắn, tức là xét độ lớn:

$$
\eta=\frac{p_{40}-p_{m n}}{p_{0}-p_{m n}}
$$

Trong đó: $p_{0,} p_{40}$ - áp suất $(\mathrm{Pa})$ trên mặt sóng 0 và sóng 40 tại vị trí cách tâm lượng nổ $\mathrm{C}_{0}$ một khoảng $R(\mathrm{~m})$ thỏa mãn $\mathrm{R} \geq \mathrm{a}+\mathrm{b}$;

$p_{m n}$ - áp suất tại mặt thoáng $(\mathrm{Pa})$.

Tù̀ (13) và (33) thay vào (44) thu được:

$$
\eta=\frac{1}{14700} \cdot\left(\frac{a+b}{r_{C 0}}\right)^{1,13} \text {. }
$$

$\left[K_{K X 23} \cdot\left(\frac{a}{a+b}\right)^{\gamma} \cdot\left(K_{K \times 12} \cdot 14700 \cdot\left(\frac{r_{C 0}}{a}\right)^{1,13}+K_{K X 12}-1\right)+K_{K X 23}-1\right]$

Gọi $m, n$ lần lượt là tỷ lệ khoảng cách vị trí đặt lượng nổ và bề dầy màn chắn bọt khí theo bán kính lượng nổ ban đầu, tức là:

$$
a=n . r_{C 0} ; b=m . r_{C 0}
$$

Thay vào (46) vào (45) ta có:

$$
\begin{aligned}
& \eta=\frac{1}{14700} \cdot(n+m)^{1,13} . \\
& {\left[K_{K \times 23} \cdot\left(\frac{n}{n+m}\right)^{\gamma} \cdot\left(K_{K \times 12} \cdot 14700 \cdot\left(\frac{1}{n}\right)^{1,13}+K_{K \times 12}-1\right)+K_{K X 23}-1\right]}
\end{aligned}
$$




\section{Nhận xét kết quả và áp dụng tính toán}

Sóng nổ lan truyền trong môi trường nước gặp màn chắn bóng khí bị phân rã thành một loạt các sóng tại hai mặt phân cách của màn chắn. Các sóng này lan truyền ngược trở lại môi trường nước chứa lượng nổ ban đầu (các sóng 1i), trong môi trường nước chứa bóng khí (các sóng $2 \mathrm{i}, 3 \mathrm{i}$ ) và môi trường phía sau màn chắn (các sóng $4 \mathrm{i}$ ). Với từng nhóm sóng (1i, 2i, 3i hoặc 4i): các sóng càng xuất hiện sau (i càng lớn) thì càng có biên độ nhỏ. Quá trình hình thành sóng mới dừng lại khi biên độ sóng $2 \mathrm{i}$ hoặc $3 \mathrm{i}$ giảm dần tới áp suất môi trường.

Nhận xét về tính chất của các sóng:

- Từ (41) và (20) suy ra: $K_{P X 12}<0$ nên sóng phản xạ 10, $1 \mathrm{i}$ là sóng dãn.

- Từ (41) và (25) suy ra: $K_{P X 23}>0$ nên sóng phản xạ 30, 3i là sóng nén.

- Từ (20) và (24) suy ra: $K_{K X 12}>0$, $K_{K X 23}>0$ nên các sóng khúc xạ $20,2 \mathrm{i}, 40,4 \mathrm{i}$ là sóng nén.

Hiệu quả suy giảm cường độ sóng nổ trong nước của màn chắn bóng khí có thể xác định theo tỷ số độ lớn của áp suất trên mặt sóng khúc xạ 40, tạo thành từ lần phân rã đầu tiên, sau màn chắn và giá trị tương ứng của áp suất sóng nổ tại vị trí đó, khi không có màn chắn và xác định theo công thức (45) hoặc (47).

Nếu môi trường II cũng là nước (tức là ba môi trường I, II, III đồng nhất là nước) thì: $K_{K X 12}=K_{K X 23}=1$ và $\gamma=1,13$. Thay vào (45), rút gọn được: $\eta=1$ tức là không có màn chắn bóng khí.

Tù̀ (45), (47) thấy rằng các yếu tố ảnh hưởng đến hiệu quả làm việc của màn chắn bóng khí là: độ dày màn chắn, khoảng cách từ lượng nổ đến màn chắn, tỷ lệ thể tích bóng khí có trong màn chắn, độ sâu khảo sát cũng như bản chất môi trường nước và khí chứa trong bóng khí.

Để có định lượng tương đối về ảnh hưởng của một số yếu tố này, thực hiện tính toán theo công thức (47) trên phần mềm toán học Maple 17 với các giả thiết về tỷ lệ thể tích bọt khí $\alpha_{k 0}$ trong môi trường II; tỷ lệ khoảng cách vị trí đặt lượng nổ $n$ và tỷ lệ bề dầy màn chắn bọt khí $m$ theo bán kính lượng nổ ban đầu và độ sâu khảo sát $w(\mathrm{~m})$, ta có các đồ thị sau:

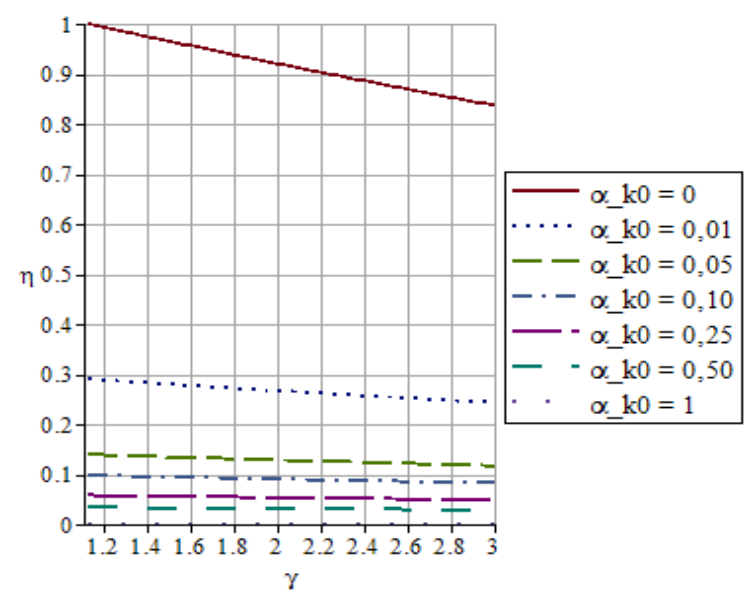

Hình 4. Tỷ lệ suy giảm áp suất trên mặt sóng do ảnh hướng của màn chắn bóng khí với $n=10$; $m=1 ; w=2 m$ thay đổi theo $\alpha_{k o}$ và $\gamma$.

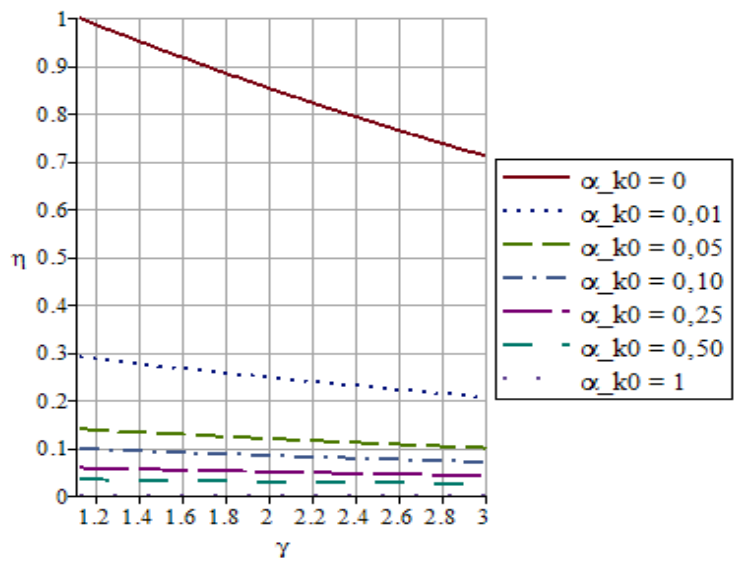

Hình 5. Tỷ lệ suy giảm áp suất trên mặt sóng do ảnh hương của màn chắn bóng khí với $n=10$; $m=2 ; w=2 m$ thay đổi theo $\alpha_{k o}$ và $\gamma$.

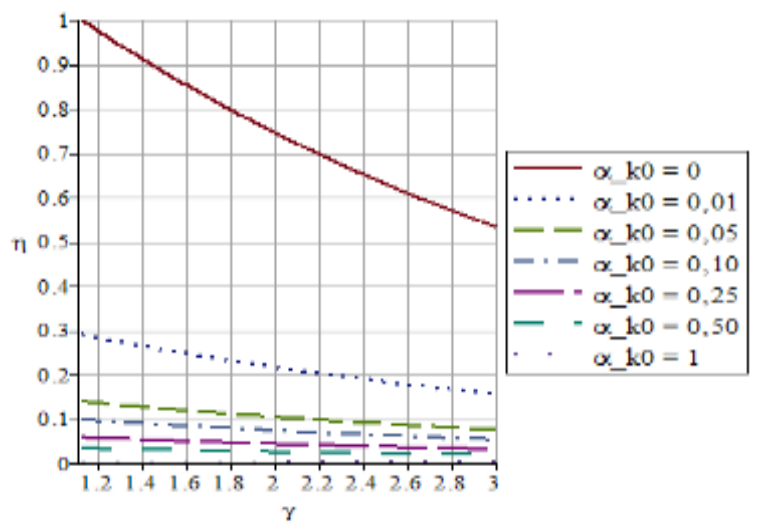

Hình 6. Tỷ lệ suy giảm áp suất trên mặt sóng do ảnh hướng của màn chắn bóng khí với $n=10$; $m=4 ; w=2 m$ thay đổi theo $\alpha_{k o}$ và $\gamma$. 


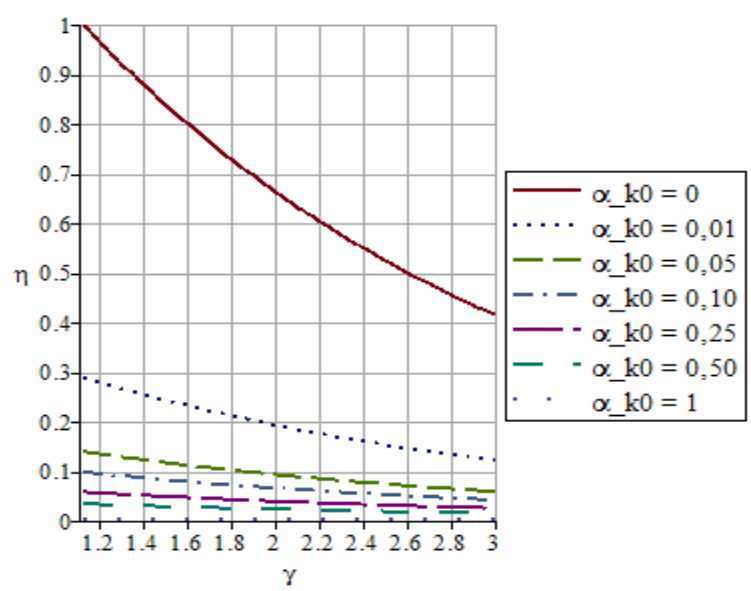

Hình 7. Tỷ lệ suy giảm áp suất trên mặt sóng do ảnh hương của màn chắn bóng khí với $n=10$; $m=6 ; w=2 m$ thay đổi theo $\alpha_{k 0}$ và $\gamma$.

Phân tích các Hình $4 \div 7$ thấy rằng:

- Tỷ lệ thể tích khí có trong màn chắn là yếu tố ảnh hưởng mạnh nhất đến hiệu quả tác dụng của màn chắn bóng khí. Chỉ cần có $1 \%$ pha khí trong thể tích môi trường nước chứa bóng khí và bố trí màn chắn cách lượng nổ một khoảng 10 lần bán kính lượng nổ, chiều dày màn chắn bằng bán kính lượng nổ thì màn chắn có thể làm giảm đến $70 \%$ áp suất trên mặt sóng nổ truyền qua nó so với trường hợp không có màn chắn ở cùng vị trí khoảng cách tới lượng nổ. Cũng với màn chắn này, nếu có $5 \%$ thể tích là pha khí thì màn chắn giảm được $85 \%$ áp suất trên mặt sóng nổ và nếu có $10 \%$ thể tích là pha khí thì có thể giảm đến $90 \%$ áp suất trên mặt sóng nổ.

- Với cùng thể tích pha khí và khoảng cách đến lượng nổ không đổi thì bề dày màn chắn bóng khí càng lớn thì hiệu quả làm suy giảm áp suất trên mặt sóng nổ càng cao. Tuy nhiên, mức độ ảnh hưởng này không rõ rệt với các màn chắn bóng khí có hàm lượng thể tích pha khí trên $1 \%$.

\section{Kết luận}

Sóng nổ lan truyền trong môi trường nước gặp màn chắn bóng khí bị phân rã thành một loạt các sóng tại hai mặt phân cách của màn chắn, gồm: các sóng giãn lan truyền ngược trở lại môi trường nước chứa lượng nổ ban đầu, các sóng nén phản xạ trong màn chắn và các sóng khúc xạ (sóng nén) lan truyền sau màn chắn. Với từng nhóm sóng: các sóng càng xuất hiện sau thì càng có biên độ nhỏ. Quá trình hình thành sóng mới dừng lại khi biên độ sóng nén phản xạ trong màn chắn giảm dần tới áp suất môi trường.

Hiệu quả làm suy giảm cường độ sóng nổ trong nước của màn chắn bóng khí có thể xác định theo công thức (45) hoặc (47). Với cùng một loại chất khí ở trong màn chắn, các yếu tố ảnh hưởng thuận đến mức độ suy giảm này là: độ dày màn chắn, khoảng cách từ lượng nổ đến màn chắn, tỷ lệ thể tích bóng khí có trong màn chắn. Trong đó, tỷ lệ thể tích khí có trong màn chắn là yếu tố ảnh hưởng mạnh nhất.

\section{Đóng góp của các tác giả}

Tác giả Đàm Trọng Thắng đề xuất ý tưởng nghiên cứu và nguyên tắc áp dụng phương pháp xác định cường độ các loại sóng theo nguyên lý lượng nổ ảo. Tác giả Trần Đức Việt thiết lập mô hình và xây dựng chương trình tính toán khảo sát ảnh hưởng của thông số màn chắn bọt khí đến cường độ sóng xung kích.

\section{Tài liệu tham khảo}

Cole R. H. (1948). Underwater explosions. Princeton University Press, New Jersey, 437 pages.

Domenico, (1982). Acoustic wave propagation in airbubble curtains in water. Geophysics, 47, 345353.

Hồ Sĩ Giao, Đàm Trọng Thắng, Lê Văn Quyển, Hoàng Tuấn Chung. (2010). Nổ hóa học lý thuyết và thực tiễn. NXB Khoa học và kỹ thuật, Hà Nội, 663 trang.

Đàm Trọng Thắng, Bui Xuan Nam, Trần Quang Hiếu. (2015). Nổ mìn trong ngành mỏ và công trình. NXB Khoa học tự nhiên và công nghệ, Hà Nội, 454 trang.

Đàm Trọng Thắng, Trần Đức Việt. (2020). Nghiên cứu ảnh hưởng độ cứng truyền âm của môi trường nước chứa bọt khí đối với tải trọng song nổ. Tạp chí Công nghiệp mỏ, 3, 5-8.

Đàm Trọng Thắng, Trần Đức Việt, Nguyễn Phú Thắng, (2020). Sự biến đổi của song nổ tại mặt phan cach giữa môi trường nước và môi trường nước chứa bong kh . Tạp chí Nghiên cúu khoa học và công nghệ quân sự, 70 thang 12-2020, 139-145.

Oplenko L. P. (2004). Explosion physics. FIZMATLIT, Moscow.

Lyakhov G. M. (1982). Equation of state of soil and porous multicomponent medium. Science, Moscow. 